\title{
Characterization of a Rat Multi-Cell Type 3D-Liver Microtissue System
}

\section{Denise V Kratschmar' ${ }^{1}$, Simon Messner ${ }^{2}$, Wolfgang Moritz ${ }^{2}$ and Alex Odermatt ${ }^{1 *}$}

${ }^{1}$ Swiss Center for Applied Human Toxicology and Division of Molecular and Systems Toxicology, Department of Pharmaceutical Sciences, University of Basel, Switzerland

${ }^{2}$ InSphero AG, Wagistrasse, Switzerland

\begin{abstract}
Background: Primary hepatocytes rapidly lose their polarized morphology and the expression of important liverspecific metabolic enzymes, receptors and transport proteins under normal two-dimensional (2D) culture conditions. Thus, their use as a reliable predictive in vitro model for drug-induced liver injury is limited. Three-dimensional (3D) liver micro tissue culture systems have become an increasingly attractive alternative for the evaluation of druginduced liver toxicity. However, several liver-specific pathways remain to be characterized in such models.
\end{abstract}

Methods and principal findings: In the present work, we compared the expression of several genes with a role in the anti-oxidant cell defense and glucocorticoid pathways in rat H4IIE hepatoma cells, primary rat hepatocytes, 2D-hepatocyte sandwich culture, and a multi-cell type micro tissue model comprising primary rat hepatocytes in coculture with liver-derived nonparenchymal cells and macrophage (Kupffer cells). Gene expression was studied for up to 25 days in culture. High expression levels of the Nrf2-dependent genes NQO1, ABCC3 and GST2A were detected in H4IIE cells and in 3D-liver microtissues, in contrast to 2D-hepatocytes where a rapid decline of these genes was observed. The glucocorticoid-dependent genes ORM1, G6PC, PCK1 and HSD11B1 were highly expressed up to 25 days of cultivation in 3D-liver microtissues, but they showed very low or background expression in H4IIE and 2D-hepatocyte models.

Conclusions: The tested 3D-multi-cell type liver micro tissue represents a stable and functionally active model system, with sustained expression for more than three weeks of cultivation of important metabolic proteins regulated by the glucocorticoid and anti-oxidant cell defense pathway.

Keywords: 3D-liver system; Microtissue; Spheroid; Glucocorticoid; 11beta-hydroxysteroid dehydrogenase; Anti-oxidant cell defense

\section{Introduction}

Drug-Induced Liver Injury (DILI) is the major severe adverse drug reaction of marketed drugs, with severe health consequences for the patients and financial loss for the pharmaceutical industry due to market withdrawal [1]. For the evaluation of safety profiles for novel drug candidates and the prediction of adverse drug effects, improved in vitro liver models are of great demand.

Available hepatic in vitro models for DILI include hepatoma cell lines, primary hepatocytes, liver microsomes and tissue slices. Although primary hepatocytes cultured as a monolayer are commonly used, their application is restricted to the assessment of acute toxicity due to limited viability, altered polarity, rapid loss of liver-specific gene expression and rapidly decreasing functionality [2,3]. Hepatocytes cultured as two-dimensional (2D) monolayers often fail to predict chronic toxicity, and only $50 \%$ of acute hepatotoxic compounds are detected [4]. Liver toxicity is often mediated by a complex interaction of hepatocytes with different cell-types such as liver-derived macrophages (Kupffer cells). Moreover, prolonged and repeated exposure to drugs and drug metabolites causing chronic rather than acute hepatotoxicity need to be considered. In contrast to isolated hepatocytes and hepatocarcinoma cell lines, Precision Cut Liver Slices (PCLS) represent a multicellular ex vivo model for the investigation of drug induced liver toxicology. Using optimized culture conditions, the viability and organ-specific architectural composition of the different cell types within rat PCLS can be maintained up to $96 \mathrm{~h}$ in culture [5,6]. However, comparable with observations in hepatocytes, the expression of genes from multiple metabolic pathways such as carbohydrate metabolism and lipid metabolism is altered in PCLS that are kept in culture for $24 \mathrm{~h}$ or longer [6,7]. Similarly, the expression of cytochrome P450 enzymes rapidly decreased after prolonged cultivation in human PCLS [8,9]. A cultivation period of $24 \mathrm{~h}$ reduced the total cytochrome P450 content in trout PCLS to $50 \%$ of that in freshly isolated PCLS [10]. Thus, the rapidly altered gene expression of PCLS upon cultivation restricts their use to short-term applications and does not allow the investigation of drug-induced subchronic toxicity $[5,11]$. In addition to their restricted metabolic activity during prolonged cultivation, a major limitation of PCLS is the requirement of complex and sophisticated dynamic culture conditions, preventing high-throughput screening applications [5].

In recent years, different approaches aimed to overcome these limitations by the use of complex culture systems in order to prolong hepatocyte viability and mimic the hepatic microenvironment. Threedimensional (3D) liver models instead of the classic 2D-monolayer cultures favor the formation of extracellular matrix and facilitate intra- and inter-cellular communication $[12,13]$. The use of 3D-culture conditions led to an improved predictive performance of hepatoma derived cell lines such as human HepG2 cells for the toxicity of commonly used drugs [14]. Cocultivation of hepatocytes with other cell types such as endothelial cells enhanced the cultivation period of

*Corresponding author: Alex Odermatt, Division of Molecular and Systems Toxicology, Department of Pharmaceutical Sciences, University of Basel, Klingelbergstrasse 50, 4056 Basel, Switzerland, Tel: +41 61267 1530; Fax: +41 61 267 1515; E-mail: alex.odermatt@unibas.ch

Received April 08, 2013; Accepted November 20, 2013; Published November 22, 2013

Citation: Kratschmar DV, Messner S, Moritz W, Odermatt A (2013) Characterization of a Rat Multi-Cell Type 3D-Liver Microtissue System. J Tissue Sci Eng 4: 130. doi:10.4172/2157-7552.1000130

Copyright: (C) 2013 Kratschmar DV, et al. This is an open-access article distributed under the terms of the Creative Commons Attribution License, which permits unrestricted use, distribution, and reproduction in any medium, provided the original author and source are credited. 
Citation: Kratschmar DV, Messner S, Moritz W, Odermatt A (2013) Characterization of a Rat Multi-Cell Type 3D-Liver Microtissue System. J Tissue Sci Eng 4: 130. doi:10.4172/2157-7552.1000130

Page 2 of 7

functional hepatocytes kept in a monolayer, while implementation of other functional cells such as macrophage mimic the in vivo situation of a multi-cell type environment and further enhance the predictive power due to inflammatory responsiveness [15-17].

Hepatocytes express essential receptors, enzymes and transport proteins involved in biotransformation and mediating the detoxification of hazardous xenobiotics and reactive endogenous compounds. By introducing oxygen into lipophilic compounds Cytochrome P450 (CYP) enzymes metabolize a vast number of chemicals. To avoid cellular damage by reactive compounds, various cytoprotective genes, including those under the control of the transcription factor nuclear factor (erythroid 2)-like 2 (Nrf2, NFE2L2 gene), are involved in conjugation reactions, export functions, defense against oxidative stress and repair mechanisms. Nrf2 is a key regulator of the anti-oxidant cell defense system that controls both basal and ligand-induced expression of important cytoprotective enzymes [18,19]. Nrf2 target genes include essential phase II detoxification enzymes such as NAD(P)H:Quinone Oxidoreductases (NQO), Hemeoxygenase-1 (HO-1, HMOX1 gene) and Glutathione S-Transferases (GST) that are induced, among other factors, by oxidative stress caused by xenobiotics [18,20-23]. The importance of Nrf2 is demonstrated in knockout mice, exhibiting an enhanced susceptibility towards oxidative stress caused by xenobiotics as a result of diminished expression of cytoprotective genes [24-26].

Another essential function of hepatocytes is the regulation of carbohydrate and lipid metabolism to preserve energy homeostasis. Carbohydrate metabolism is sustained among others by the action of the Glucocorticoid Receptor (GR). Hepatic GR function depends on the circulating concentration of glucocorticoids produced by the adrenal glands and on the activity of hepatic $11 \beta$-hydroxysteroid dehydrogenase 1 (11 $\beta$-HSD1), converting the inactive 11-ketoglucocorticoids cortisone and 11-dehydrocorticosterone into their active $11 \beta$-hydroxyls cortisol and corticosterone [27]. 11 $\beta$-HSD1 is facing the Endoplasmic Reticulum (ER) and requires NADPH as cofactor, which is directly provided by Hexose-6-Phosphate Dehydrogenase (H6PDH) [28-30]. By utilizing glucose-6-phosphate, H6PDH controls the NADPH/ $\mathrm{NADP}^{+}$redox couple in the ER and constitutes an important link between carbohydrate metabolism and glucocorticoid activation, thereby acting as a nutritional energy sensor $[31,32]$.

We recently reported a suppression of Nrf2 activity by glucocorticoids using H4IIE cells and a clone stably expressing $11 \beta-H S D 1$ [33]. Despite of the importance of the glucocorticoid and antioxidant cell defense pathway, there has been little effort so far to characterize in vitro liver models for the expression of essential GRand Nrf2-dependent genes. We therefore aimed in the present study to characterize a promising rat 3D-multi-cell liver microtissue system for the expression of genes of these two pathways.

\section{Experimental Procedure}

\section{Materials and methods}

Rat liver microtissues (3D InSight ${ }^{\mathrm{TM}}$ Rat Liver Microtissues) were obtained from InSphero AG, Schlieren, and Switzerland in a 96-well format (Gravity TRAP ${ }^{\mathrm{TM}}$ ). Cell culture media was purchased from Invitrogen (Carlsbad, CA), $\left[1,2-{ }^{3} \mathrm{H}\right]$-cortisone from American Radiolabeled Chemicals (St.Louis, MO), and all other chemicals were from Fluka AG (Buchs, Switzerland).

\section{Cell culture}

Rat H4IIE hepatoma cells and H4IIE cells stably expressing
$11 \beta$-HSD1 (clone H4H1)) were cultured in Dulbecco's Modified Eagle Medium (DMEM) supplemented with 10\% fetal bovine serum, $4.5 \mathrm{~g} / \mathrm{L}$ glucose, $50 \mathrm{U} / \mathrm{mL}$ penicillin/streptomycin, $2 \mathrm{mM}$ glutamine, and $1 \mathrm{mM}$ HEPES, pH 7.4, as described previously [34].

Rat liver microtissues were produced from freshly isolated rat (Wistar) hepatocytes, applying a modified isolation protocol adapted from Seglen et al. [35] that were co-cultured with nonparenchymal liver cells, derived from the same donor rat. Reaggregation of the liver cells to spheroids was achieved by culturing the cell suspension in the Gravity PLUS ${ }^{\mathrm{TM}}$ hanging drop plate and subsequent transfer into the microtissue culture and assay plate Gravity TRAP ${ }^{\mathrm{TM}}$ (InSphero Cat.\# CS-06-001) provided with the corresponding maintenance medium (CS-07-002) (Figures 1-2).

\section{Microtissue production}

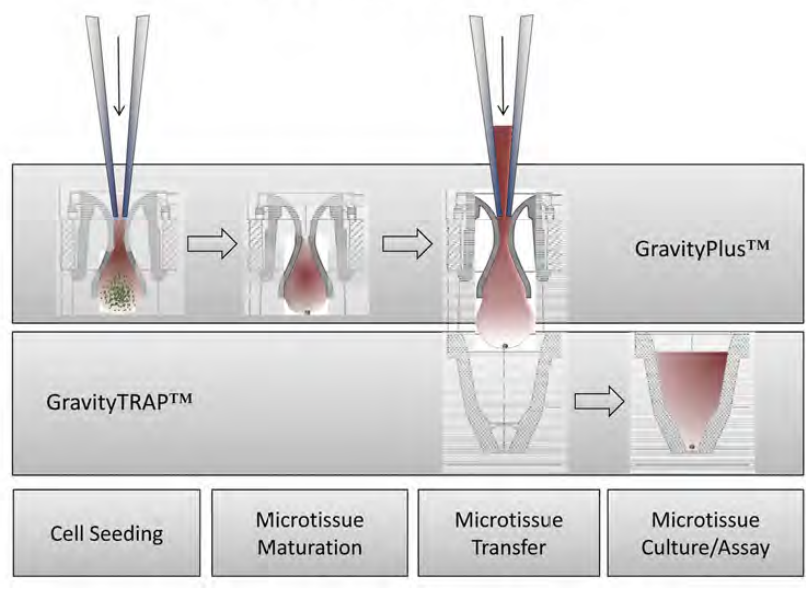

Figure 1: Schematic representation of 3D-liver microtissue production.

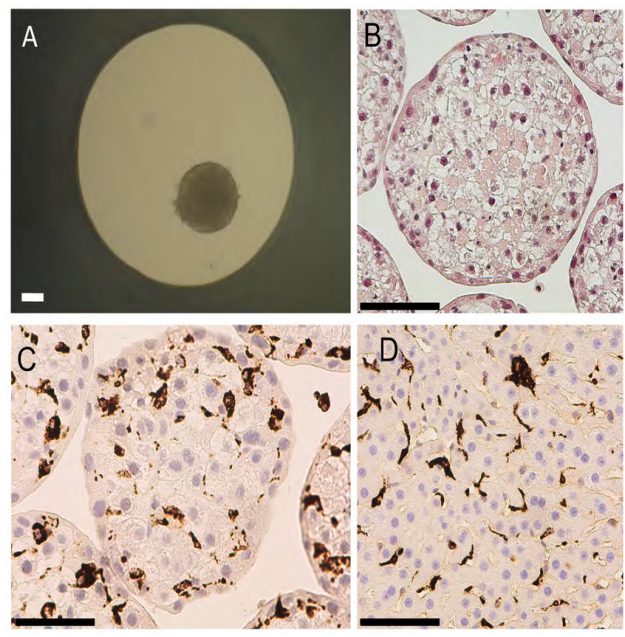

Figure 2: Morphology of rat 3D-liver microtissue at day 4.

(A) Single rat 3D-liver microtissue, composed of primary hepatocytes and non-parenchymal cells as provided in a microtiter plate format (1 microtissue/well). Bar $=200 \mu \mathrm{m}$. Size analysis of several single microtissues: diameter $319 \pm 9 \mu \mathrm{m}$; volume $0.0194 \pm 0.0014 \mu \mathrm{m}^{3}, \mathrm{n}=13$. Paraffin sections of rat 3D-liver microtissues stained by (B) hemalaun and eosin and (C) anti-CD68 antibody for the identification of Kupffer cells. (D) Native rat liver section stained for CD68. Bar=100 $\mu \mathrm{m}$. 
Citation: Kratschmar DV, Messner S, Moritz W, Odermatt A (2013) Characterization of a Rat Multi-Cell Type 3D-Liver Microtissue System. J Tissue Sci Eng 4: 130. doi:10.4172/2157-7552.1000130

Page 3 of 7

\section{Analysis of mRNA expression by real-time RT-PCR}

For each time point total RNA was extracted from microtissues of 96-well plates using the RNA extraction protocol of the RNeasy Mini Kit Isolation System including on-column DNase digestion with the RNase-Free DNase Set according to the manufacturer's protocol (Qiagen, Basel Switzerland). H4IIE and H4H1 cells (500'000 cells/ well) were cultivated in 24-well plates containing DMEM for $24 \mathrm{~h}$ at $37^{\circ} \mathrm{C}$. Total mRNA was extracted using the Trizol method (Invitrogen, Carlsbad, CA). Total mRNA from hepatoma cells $(2 \mu \mathrm{g})$ or micro tissues (200 ng) was reverse transcribed to cDNA using the SuperscriptIII First-Strand Synthesis System and oligo-dT from Invitrogen. Relative quantification of mRNA expression levels was performed by RT-PCR on a RotorGene 6000 (Corbett, Sydney, Australia) using the KAPA SYBR ${ }^{\circledR}$ FAST qPCR Kit (Kapasystems, Boston, MA). Relative gene expression compared with the internal control PPIA was determined using the delta-delta-CT method. The following oligonucleotide primer pairs were used for real-time RT-PCR: Peptidylprolyl Isomerase A (PPIA) Forward (FW): 5'-ATTCATGTGCCAGGGTGGTG-3', Reverse (RV): 5'-GGACCTGTATGCTTCAGGATG-3'; Phosphoenolpyruvate Carboxykinase 1 (PCK1) FW: 5-TCCCATTGGCTACGTCCCTAA-3', RV: 5'-CCACCTCCTTCTCCCAGAATTC-3'; ATPBinding Cassette, Subfamily C (CFTR/MRP)member 3 (ABCC3) FW: 5'-TCCCACTTCTCGGAGACAGTAACT-3', RV: 5'- CACCTTAGCATCACTGAGGACCTT; Orosomucoid 1 (ORM1) FW: 5'GTTCTGGGTTCTGAGCTTCCAA-3'， RV： 5'-CGCTGCACATGGTTCTTGTC-3'; NAD(P)H dehydrogenase, Quinone 1 (NQO1) FW: 5'-GCCTTTGTTCCACAAGGATAGG-3', RV: 5'- GCCCCTAATCTGACCTCGTT-3'; Glucose-6-Phosphate Dehydrogenase (G6PD) FW: 5'- GCCTTCTACCCGAAGACACCTT-3'， RV: 5'-CTGTTTGCGGATGTCATCCA-3'; Glutathione S-Transferase A2 (GST2A) FW: 5'-CAGGAGTGGAGTTTGATGAG-3'，RV: 5'- GCGATGTAGTTGAGAATGG-3; Nuclear Factor, Erythroid Derived 2, Like 2 (NFE2L2) FW: 5'- TGCCCCTGGAAGTGTCAAA-3', RV: 5'-GGCTGTACTGTATCCCCAGAAGA-3'; Glucose- 6-Phosphatase, Catalytic Subunit (G6PC) FW: 5'-GGCTCACTTTCCCCATCAGG-3, RV: 5'- ATCCAAGTGCGAAACCAAACAG-3; Hexose-6-Phosphate Dehydrogenase (H6PD) FW: 5'-GCAGAAGAGCAACGCCAT-3', RV: 5'-GAACATAGCCGACTCTCTCG-3; 11 $\beta$-Hydroxysteroid Dehydrogenase
1 (HSD11B1) FW: 5'-GAAACAGAGCAATGGCAGCAT-3', RV: 5'-CAAACTTGCTTGCAGAGTAGGAAG-3'.

\section{Measurement of 11 $\beta$-HSD1 enzyme activity in intact 3D-liver microtissues}

3D-liver microtissues from two independent hepatic isolations were cultivated for up to 25 days in hanging drop cultivation plates. Medium was replaced every third day by fresh culture medium. At 48 $\mathrm{h}$ prior to the enzyme assay, thirty $3 \mathrm{D}$-microtissues were collected in a $10 \mathrm{~cm}^{2}$ dish containing PBS at $37^{\circ} \mathrm{C}$. Subsequently, microtissues were transferred into a $10 \mathrm{~cm}^{2}$ dish containing culture medium without dexamethasone. Five microtissues per condition were placed into one well of a GTRAP assay plate. Microtissue spheroids were then incubated for $48 \mathrm{~h}$ in medium $(80 \mu \mathrm{L})$ without dexamethasone. The medium was removed and replaced by assay medium (Bioconcept HHMM_CT) containing $50 \mathrm{nM}$ of cortisone with $10 \mathrm{nCi}[3 \mathrm{H}]$-cortisone as tracer in the presence or absence of the selective $11 \beta$-HSD1 inhibitor T0504 (1 $\mu \mathrm{M})$, followed by incubation for $24 \mathrm{~h}$ at $37^{\circ} \mathrm{C}$. Reactions were stopped by adding methanol containing $2 \mathrm{mM}$ of unlabeled cortisone and cortisol, followed by separation of steroids by TLC and scintillation counting.

\section{Results}

Comparison of gene expression of glucocorticoid and antioxidant cell defense pathway in different in vitro liver models

In order to validate the $3 \mathrm{D}$-liver microtissue system for studies of the glucocorticoid and anti-oxidant cell defense pathways, we compared the mRNA expression levels of genes regulated by these two pathways between the rat 3D-liver microtissue system, rat hepatocytes in 2D-sandwich culture and the rat hepatoma cell line H4IIE (Table 1) (Figures 1-2). Further, we included a H4IIE cell clone stably expressing $11 \beta$-HSD1 (H4H1). PCLS were not included in the study because they cannot be cultured for longer than 72-96 h. Quantification of mRNA levels by real time RT-PCR requires an appropriate internal standard, which is constantly expressed throughout the experiment [36]. We used the widely accepted house-keeping gene PPIA, encoding cyclophilin A, for normalization of the expression levels of interest. PPIA mRNA expression stayed constant during the time of the experiment and upon

\begin{tabular}{|c|c|c|c|c|c|c|}
\hline \multirow[t]{2}{*}{ Gene name } & \multirow[t]{2}{*}{ H4IIE } & \multirow[t]{2}{*}{$\mathrm{H} 4 \mathrm{H} 1$} & \multicolumn{2}{|c|}{ 2D-hepatocyte sandwich } & \multicolumn{2}{|c|}{ 3D-liver microtissue } \\
\hline & & & Day 4 & Day 25 & Day 4 & Day 25 \\
\hline \multicolumn{7}{|c|}{ Glucocorticoid pathway } \\
\hline PCK1 & $32.0 \pm 0.8$ & $21.4 \pm 1.2$ & $33.5 \pm 1.3$ & $34.3 \pm 1.7$ & $25.5 \pm 0.4$ & $27.5 \pm 0.1$ \\
\hline ORM1 & $30.1 \pm 0.4$ & $30.0 \pm 0.2$ & $20.5 \pm 2.3$ & $25.4 \pm 0.3$ & $19.6 \pm 1.3$ & $21.7 \pm 1.0$ \\
\hline G6PC & $32.3 \pm 1.9$ & $21.5 \pm 0.5$ & $34.2 \pm 0.6$ & $34.1 \pm 0.7$ & $27.1 \pm 0.6$ & $27.4 \pm 0.1$ \\
\hline$H 6 P D$ & $29.5 \pm 1.1$ & $30.5 \pm 0.5$ & $34.1 \pm 3.3$ & $35.9 \pm 0.3$ & $30.5 \pm 0.6$ & $30.8 \pm 0.5$ \\
\hline H11B1 & $34.7 \pm 0.1$ & $27.3 \pm 0.6$ & $31.1 \pm 0.4$ & $33.7 \pm 4.9$ & $24.2 \pm 0.9$ & $23.4 \pm 0.4$ \\
\hline \multicolumn{7}{|c|}{ Anti-oxidant cell defense pathway } \\
\hline$A B C C 3$ & $27.0 \pm 0.6$ & $27.7 \pm 0.3$ & $28.8 \pm 1.3$ & $31.6 \pm 1.9$ & $27.8 \pm 1.6$ & $28.7 \pm 1.2$ \\
\hline NQ01 & $24.8 \pm 0.4$ & $22.9 \pm 0.6$ & $28.6 \pm 0.2$ & $30.7 \pm 2.1$ & $25.6 \pm 2.5$ & $27.0 \pm 1.0$ \\
\hline GSTA2 & $24.8 \pm 1.7$ & $28.8 \pm 0.6$ & $30.9 \pm 1.6$ & $33.0 \pm 0.7$ & $20.5 \pm 0.9$ & $21.0 \pm 1.2$ \\
\hline NFE2L2 & $21.3 \pm 0.5$ & $20.5 \pm 0.9$ & $28.3 \pm 2.2$ & $30.6 \pm 2.0$ & $25.1 \pm 1.9$ & $24.9 \pm 0.1$ \\
\hline \multicolumn{7}{|c|}{ Other (redox pathway) } \\
\hline G6PD & $23.9 \pm 0.8$ & $24.7 \pm 0.2$ & $28.4 \pm 0.2$ & $30.9 \pm 1.9$ & $28.4 \pm 1.2$ & $29.0 \pm 1.7$ \\
\hline \multicolumn{7}{|l|}{ House-keeping } \\
\hline PPIA & $24.1 \pm 0.2$ & $19.2 \pm 0.1$ & $22.8 \pm 0.5$ & $23.5 \pm 0.8$ & $22.3 \pm 0.1$ & $21.8 \pm 0.7$ \\
\hline
\end{tabular}

Table 1: Overview of mRNA expression levels in rat liver in vitro models.

The mRNA expression levels of genes of the glucocorticoid- and anti-oxidant cell defense pathways were determined by real-time RT-PCR. Peptidyl prolyl isomerase A (PPIA) served as a house-keeping gene to normalize expression levels of the corresponding gene of interest. Data represent mean \pm SD. 
the treatment applied. The CT-values measured for the different liver models were in a similar range (between 22-24).

A comparison of the expression of genes that are regulated by Glucocorticoid Receptors (GR) revealed low or background levels in H4IIE hepatoma cells with CT-values higher than 30, except for H6PD, which despite the relatively high CT-value of 29.5 is functionally expressed in these cells and in the stable line $\mathrm{H} 4 \mathrm{H} 1$ [37]. In the 2D-sandwich culture system ORM1 was expressed at high levels up to day 4 (CT of 20.5), followed by a rapid decline in its expression until day 25 (CT of 25.4). All other glucocorticoid-dependent genes were detected at background levels only. In contrast, the 3D-liver spheroid system expressed substantial levels of the glucocorticoid-dependent genes ORM1, PCK1, G6PC and HSD11B1, and no or only a slight decrease was observed after another three weeks in culture. HSD11B1 expression levels in the 3D-liver microtissues were higher than in the stably transfected $\mathrm{H} 4 \mathrm{H} 1$ hepatoma cell clone. The lowest expression was detected for H6PDH, which was also retained up to day 25 of cultivation. The expression in the 3D-liver spheroid system, although moderate, was clearly higher than that in the 2D-hepatocyte sandwich culture model.

In contrast to glucocorticoid-dependent genes, genes involved in anti-oxidant cell defense, i.e. Nrf2, NQO1, ABCC3 and GST2A, are expressed at substantial levels in H4IIE. These genes are also highly expressed in the 3D-liver spheroid model, with highest expression observed for GST2A. Importantly, the expression of these genes was retained during the three week cultivation period. Much lower expression levels were found in the 2D-hepatocyte culture, and the expression further dropped upon cultivation for three weeks. As an additional gene with a role in redox regulation, but not under the control of Nrf2, we determined the expression of G6PDH in the different liver models. Similar expression of G6PDH was observed in the 2D- and $3 \mathrm{D}$ model; however, the decrease in its expression was more pronounced in the 2D-system. Clearly highest G6PDH expression was found in H4IIE cells.

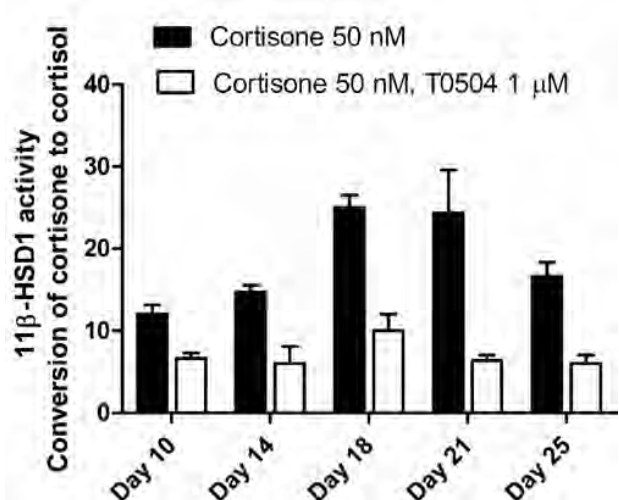

Figure 3: Functional activity of $11 \beta-H S D 1$ in intact 3D-liver microtissues over 25-days of cultivation.

Five 3D-liver microtissues were combined on day seven of cultivation into one well of the assay plate (GTRAP). Microtissue spheroids were cultured in medium without dexamethasone for another $48 \mathrm{~h}$. Medium was the removed and replaced by assay medium containing $50 \mathrm{nM}$ radiolabeled cortisone with or without $1 \mu \mathrm{M}$ of the selective $11 \beta$-HSD1 inhibitor T0504, followed by $24 \mathrm{~h}$ incubation at $37^{\circ} \mathrm{C}$. Data (mean $\pm \mathrm{SD}$ ) were obtained from two independent hepatic isolations and each data point was measured in triplicate.

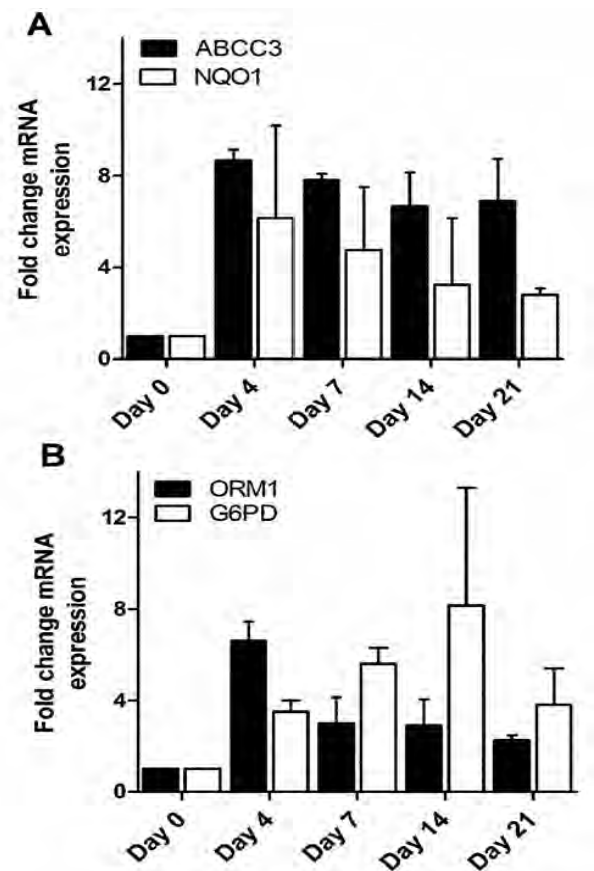

Figure 4: Enhanced mRNA expression of Nrf2- and GR-dependent genes in 3D-liver microtissues compared with freshly isolated hepatocytes. Cells were isolated from rat livers and 3D-liver spheroids were cultivated for three weeks in the hanging drop culture at $37^{\circ} \mathrm{C}$, followed by quantification of mRNA levels by real-time RT-PCR. Data (mean \pm SEM) were obtained from two independent isolations and measurements were performed in triplicate. Data represent ratios of ABCC3, NQO1, ORM1 and G6PD mRNA to PPIA control mRNA from 3Dliver microtissues normalized to the values obtained from fresh isolated liver cells.

\section{Retained 11 $\beta$-HSD1 enzyme activity over 25 days in 3D-liver microtissue cultures}

To assess whether HSD11B1 mRNA expression translates into functional enzyme in 3D-liver microtissue cultures, we measured the $11 \beta-H S D 1-d e p e n d e n t$ reduction of radiolabeled cortisone to cortisol at different time points up to 25-days in culture (Figure 3). Five 3D-liver microtissues were added into one well of the assay plate and incubated in $80 \mu \mathrm{L}$ medium supplemented with $50 \mathrm{nM}$ cortisone containing $10 \mathrm{nCi}[1,2-3 \mathrm{H}]$-cortisone in the presence or absence of 1 $\mu \mathrm{M}$ of the selective $11 \beta$-HSD 1 inhibitor T0504 for $24 \mathrm{~h}$ at $37^{\circ} \mathrm{C}$. At all time points $11 \beta-H S D 1$ enzyme activity in the presence of vehicle was significantly higher compared with microtissues treated with T0504. The $11 \beta$-HSD1-dependent cortisone reductase activity increased during cultivation up to day 18 , reaching maximal activity between days 18-21, followed slightly lower levels at day 25 . Considering the number of cells, incubation volume and reaction time, the cortisone reductase activity of the cultured spheroids can be roughly estimated to be 3-4 times lower and 6-8 times lower than that of freshly isolated rat hepatocytes and $\mathrm{H} 4 \mathrm{H} 1$ cells expressing recombinant $11 \beta$-HSD1, respectively. Nevertheless, the limited access of the substrate to the enzyme in the 3D spheroid culture compared with $2 \mathrm{D}$ cultured cells needs to be considered.

Comparison of the anti-oxidant response- and GR-dependent gene expression in 3D-liver microtissues and freshly isolated hepatocytes

Next, we compared the expression of the Nrf2- and GR-dependent 
A
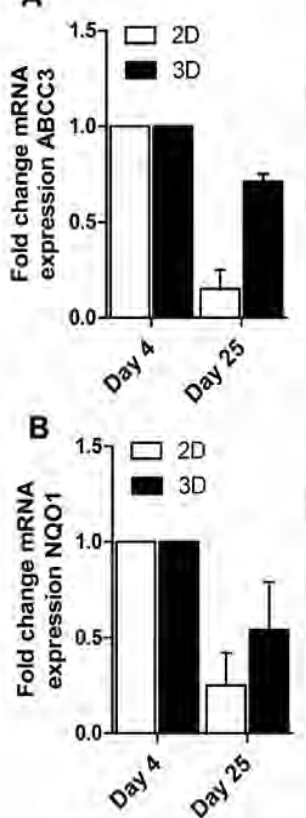

C

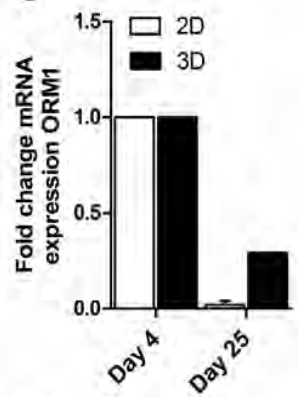

D

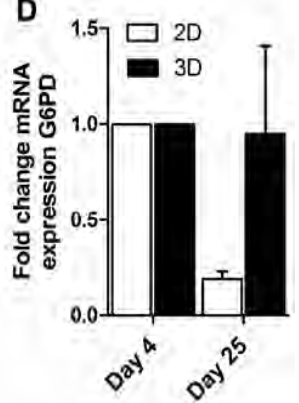

Figure 5: Sustained mRNA expression of Nrf2- and GR-dependent genes in 3D-liver microtissues.

Freshly isolated liver cells were cultivated as 2D-sandwich monolayers or as 3Dspheroids in hanging drop cultures for three weeks at $37^{\circ} \mathrm{C}$ followed by quantification of mRNA levels by real-time RT-PCR. Data (mean \pm SEM) were obtained from two independent isolations, measured in triplicate, and represent ratios of $A B C C 3, N Q 01, O R M 1$ and G6PD mRNA to PPIA control mRNA from 3D-spheroids or 2D-hepatocyte monolayers normalized to the values obtained after day four.

target genes in freshly isolated rat hepatocytes (designated as day 0 in Figure 4) with that of 3D-liver spheroids for up to three weeks of cultivation. The mRNA expression of the multi-drug resistant protein Abcc3 (Figure 4A, black bars) and the NADPH dependent quinone reductase NQO1 were eight- and five-fold increased in 3D-liver microtissues compared with freshly isolated hepatocytes. The expression of NQO1 mRNA decreased in a time-dependent way but was still three-fold higher at day 21 than the initial levels in freshly isolated hepatocytes. ABCC3 mRNA levels remained relatively constant over the three weeks cultivation period. Furthermore, the mRNA expression of both GR dependent genes G6PD and ORM1 was elevated in 3D-liver microtissues compared with freshly isolated hepatocytes derived from the same liver. ORM1 mRNA expression (Figure 4B, black bars) was highest (seven-fold) at day four after the isolation and stayed elevated (three-fold) during further cultivation. G6PD mRNA expression (Figure 4B, white bars) increased time-dependently from four-fold at day four up to eight-fold at day 14 , with a decline in mRNA expression after three weeks in culture.

Comparison of time-dependent gene expression in 2D-hepatocyte culture and 3D-liver microtissues

To further compare the time-dependent gene expression in 2D-hepatocyte monolayers (Figure 5, white bars) and 3D-liver microtissues (black bars) we measured mRNA expression after fourand 25 days of cultivation, whereby the values obtained at day 4 were set as 1 . The mRNA expression of the genes analyzed declined after three weeks in culture, except for G6PD in the 3D-spheroids. However,

all genes analyzed were expressed at significantly higher levels in the 3D-liver microtissue system.

\section{Discussion}

Functional hepatic tissue essentially maintains the glucocorticoiddependent regulation of lipid and carbohydrate homeostasis in vivo. The local hepatic glucocorticoid supply is mediated by $11 \beta$-HSD 1 , an enzyme whose expression is altered by inflammatory cytokines and NF$\kappa \mathrm{B}$, nutritional factors such as glucose and fructose and pharmaceuticals such as glucocorticoids and PPARa and PPAR $\gamma$ agonists [27, 38-40]. Currently, no suitable hepatocellular lines are available that express $11 \beta$-HSD1 as well as key enzymes responsible for glucose homeostasis. Moreover, a rapid decline of $11 \beta$-HSD 1 reductase activity is observed upon cultivating freshly isolated primary hepatocytes, with almost complete loss after $48 \mathrm{~h}$ in culture [27]. Similarly, rat PCLS rapidly lose their liver-specific gene expression and, in addition, tissue fibrosis leads to stellate cell activation within $48 \mathrm{~h}$ of cultivation, which restricts the use of PCLS to short-term applications [6]. Impaired local glucocorticoid supply also affects the function of key gluconeogenic enzymes including Phosphoenolpyruvate Carboxykinase (Pck1), Glucose-6-Phosphatase (G6Pase) and Hexose-6-Phosphate Dehydrogenase (H6PDH) [41]. Our results reveal a high expression of glucocorticoid-dependent genes such as PCK1, G6Pc, ORM1 and HSD11B1. Importantly, the expression of these genes is sustained up to 25 days in culture, allowing studying subchronic situations. Moreover, $11 \beta$-HSD1 is functionally expressed and cortisone reductase activity can readily be measured.

Current in vitro hepatic model systems often fail to predict hepatic injury because of the rapid loss of expression of phase I and II biotransformation enzymes and efflux pumps during cultivation [42]. Hepatocytes cultured as monolayers rapidly lose the expression and functional activities of key cytochrome P450 enzymes, multi-drug resistance proteins, proteins required for albumin and transferring, and glucocorticoid regeneration within the first 24-48 $\mathrm{h}$ [43-45]. The prediction of drug-induced hepatotoxicity needs to consider bioactivation as well as detoxification and clearance of reactive metabolites. Many of the genes involved in coping with oxidative damage of reactive metabolites are under the transcriptional control of Nrf2. The induction of the Nrf2-dependent anti-oxidant defense system was shown to enhance the metabolism of acetaminophen by the use of a sophisticated culture approach, which predicted toxicity more reliably than the widely used 2D-hepatocyte cultures [46]. Our results show that the expression of several Nrf2 regulated genes is maintained at high levels in 3D-liver microtissues, in contrast to 2D-hepatocyte sandwich cultures where the expression is rapidly lost. Similar levels of the Nrf2-dependent genes that were investigated in this study are expressed in the H4IIE cell line, making them a suitable system to study some mechanistic aspects of the Nrf2 pathway. This cell system is of limited use, however, for studies on the impact of glucocorticoids on xenobiotics metabolism and transport as well as interactions between the glucocorticoid and the Nrf2 pathway. Moreover, since the expression of the genes is maintained for up to 25 days, the effects of subchronic exposure to xenobiotics can be investigated in the 3D-liver microtissue system. Physiologically, the multi-functionality of the liver is ensured by the complex interactions of different cell types. Hepatotoxicity is not solely caused by impaired hepatocyte function but may result from damages of bile canalicular cells, sinusoidal epithelial cells, stellate or Kupffer cells, leading to functional changes and indirect damages of hepatocytes $[17,47]$. Thus, improved in vitro models ideally represent the interactions of different hepatic cell-types. Monocultures of hepatocytes are prone to underestimate toxic effects 
for drugs such as diclofenac or trovafloxacin that require inflammatory responsiveness to induce severe toxicity [17]. Hepatotoxicity induced by approved drugs is relatively rare, because of the preclinical use of in vitro models, animals and clinical trials in humans. Nevertheless, DILI remains the most frequent reason for post-market drug withdrawal, justifying the extensive efforts to detect adverse drug effects as early as possible. Prediction of hepatotoxicity requires reliable test systems that maintain phenotypic characteristics and concern hepatic complexity by the use of improved and sophisticated culture conditions as well as multi-cell-type models [42]. In conclusion, our study demonstrates the maintained expression of key genes of the glucocorticoid and Nrf2 pathways for up to 25 days in a 3D-multi-cell type rat liver microtissue system and emphasizes the benefits over 2D-hepatocyte cultures in static sandwich monolayers and H4IIE hepatoma cells to study interactions between these pathways. The availability of 3Dliver microtissues in 96-well format is necessary for medium- and highthroughput screening experiments.

\section{Acknowledgements}

AO and DVK were supported by a grant from the Swiss Center of Applied Human Toxicology.

\section{References}

1. Lee KS, Oh SJ, Kim HM, Lee KH, Kim SK (2011) Assessment of reactive metabolites in drug-induced liver injury. Arch Pharm Res 34: 1879-1886.

2. Abu-Absi SF, Friend JR, Hansen LK, Hu WS (2002) Structural polarity and functional bile canaliculi in rat hepatocyte spheroids. Exp Cell Res 274: 56-67.

3. Brophy CM, Luebke-Wheeler JL, Amiot BP, Khan H, Remmel RP, et al. (2009) Rat hepatocyte spheroids formed by rocked technique maintain differentiated hepatocyte gene expression and function. Hepatology 49: 578-586.

4. Castell JV, Gomez-Lechon MJ (2009) Liver cell culture techniques. Methods Mol Biol 481: 35-46.

5. de Graaf IA, Olinga P, de Jager MH, Merema MT, de Kanter R, et al. (2010) Preparation and incubation of precision-cut liver and intestinal slices for application in drug metabolism and toxicity studies. Nat Protoc 5: 1540-1551.

6. Vickers AE, Saulnier M, Cruz E, Merema MT, Rose K, et al. (2004) Organ slice viability extended for pathway characterization: an in vitro model to investigate fibrosis. Toxicol Sci 82: 534-544.

7. Hadi M, Westra IM, Starokozhko V, Dragovic S, Merema MT, et al. (2013) Human precision-cut liver slices as an ex vivo model to study idiosyncratic drug-induced liver injury. Chem Res Toxicol 26: 710-720.

8. Elferink MG, Olinga P, van Leeuwen EM, Bauerschmidt S, Polman J, et al (2011) Gene expression analysis of precision-cut human liver slices indicates stable expression of ADME-Tox related genes. Toxicol Appl Pharmacol 253: 57-69.

9. Wright MC, Paine AJ (1992) Evidence that the loss of rat liver cytochrome P450 in vitro is not solely associated with the use of collagenase, the loss of cell-cell contacts and/or the absence of an extracellular matrix. Biochem Pharmacol 43: $237-243$

10. Cravedi JP, Perdu-Durand E, Paris A (1998) Cytochrome P450-dependent metabolic pathways and glucuronidation in trout liver slices. Comp Biochem Physiol C Pharmacol Toxicol Endocrinol 121: 267-275.

11. Lerche-Langrand C, Toutain HJ (2000) Precision-cut liver slices: characteristics and use for in vitro pharmaco-toxicology. Toxicology 153: 221-253.

12. Daus AW, Goldhammer M, Layer PG, Thielemann C (2011) Electromagnetic exposure of scaffold-free three-dimensional cell culture systems. Bioelectromagnetics 32: 351-359.

13. Griffith LG, Swartz MA (2006) Capturing complex 3D tissue physiology in vitro. Nat Rev Mol Cell Biol 7: 211-224.

14. Fey SJ, Wrzesinski K (2012) Determination of drug toxicity using 3D spheroids constructed from an immortal human hepatocyte cell line. Toxicol Sci 127: 403411.

15. Kim K, Ohashi K, Utoh R, Kano K, Okano T (2012) Preserved liver-specific functions of hepatocytes in 3D co-culture with endothelial cell sheets. Biomaterials 33: 1406-1413.

16. Kostadinova R, Boess F, Applegate D, Suter L, Weiser T, et al. (2013) A longterm three dimensional liver co-culture system for improved prediction of clinically relevant drug-induced hepatotoxicity. Toxicol Appl Pharmacol 268 1-16.

17. Messner S, Agarkova I, Moritz W, Kelm JM (2013) Multi-cell type human live microtissues for hepatotoxicity testing. Arch Toxicol 87: 209-213.

18. Copple IM, Goldring CE, Kitteringham NR, Park BK (2008) The Nrf2-Keap1 defence pathway: role in protection against drug-induced toxicity. Toxicology 246: 24-33.

19. Jaiswal AK (2004) Nrf2 signaling in coordinated activation of antioxidant gene expression. Free Radic Biol Med 36: 1199-1207.

20. Venugopal R, Jaiswal AK (1996) Nrf1 and Nrf2 positively and c-Fos and Fra1 negatively regulate the human antioxidant response element-mediated expression of $\mathrm{NAD}(\mathrm{P}) \mathrm{H}$ :quinone oxidoreductase1 gene. Proc Natl Acad Sci U S A 93: 14960-14965.

21. Alam J, Stewart D, Touchard C, Boinapally S, Choi A M, et al. (1999) Nrf2, Cap'n'Collar transcription factor, regulates induction of the heme oxygenase-1 gene. J Biol Chem 274: 26071-26078.

22. McMahon M, Itoh K, Yamamoto M, Chanas S A, Henderson C J, et al. (2001) The Cap'n'Collar basic leucine zipper transcription factor Nrf2 (NF-E2 p45related factor 2) controls both constitutive and inducible expression of intestinal detoxification and glutathione biosynthetic enzymes. Cancer Res 61: 3299 3307

23. Chan K, Han XD, Kan YW (2001) An important function of Nrf2 in combating oxidative stress: detoxification of acetaminophen. Proc Natl Acad Sci U S A 98: 4611-4616.

24. Itoh K, Chiba T, Takahashi S, Ishii T, Igarashi K, et al. (1997) An Nrf2/smal Maf heterodimer mediates the induction of phase II detoxifying enzyme genes through antioxidant response elements. Biochem Biophys Res Commun 236: 313-322.

25. Kitamura Y, Umemura T, Kanki K, Kodama Y, Kitamoto S, et al. (2007) Increased susceptibility to hepatocarcinogenicity of Nrf2-deficient mice exposed to 2-amino-3-methylimidazo[4,5-f]quinoline. Cancer Sci 98: 19-24.

26. Kwak MK, Itoh K, Yamamoto M, Sutter TR, Kensler TW (2001) Role of transcription factor Nrf2 in the induction of hepatic phase 2 and antioxidative enzymes in vivo by the cancer chemoprotective agent, 3H-1, 2-dimethiole-3thione. Mol Med 7: 135-145.

27. Tomlinson JW, Walker EA, Bujalska IJ, Draper N, Lavery GG, et al. (2004) $11 \beta$-hydroxysteroid dehydrogenase type 1: a tissue-specific regulator of glucocorticoid response. Endocr Rev 25: 831-866.

28. Atanasov AG, Nashev LG, Gelman L, Legeza B, Sack R, et al. (2008) Direct protein-protein interaction of 11/-hydroxysteroid dehydrogenase type 1 and hexose-6-phosphate dehydrogenase in the endoplasmic reticulum lumen Biochim Biophys Acta 1783: 1536-1543.

29. Atanasov AG, Nashev LG, Schweizer RA, Frick C, Odermatt A (2004) Hexose-6- phosphate dehydrogenase determines the reaction direction of $11 \beta$-hydroxysteroid dehydrogenase type 1 as an oxoreductase. FEBS Lett 571 129-133.

30. Lavery GG, Walker EA, Draper N, Jeyasuria P, Marcos J, et al. (2006) Hexose-6-phosphate dehydrogenase knock-out mice lack $11 \beta$-hydroxysteroid dehydrogenase type 1-mediated glucocorticoid generation. J Biol Chem 281 6546-6551.

31. Dzyakanchuk AA, Balázs Z, Nashev LG, Amrein KE, Odermatt A (2009) $11 \beta$-Hydroxysteroid dehydrogenase 1 reductase activity is dependent on a high ratio of NADPH/NADP(+) and is stimulated by extracellular glucose. Mol Cell Endocrinol 301: 137-141.

32. Lavery GG, Hauton D, Hewitt KN, Brice SM, Sherlock M, et al. (2007) Hypoglycemia with enhanced hepatic glycogen synthesis in recombinant mice lacking hexose-6-phosphate dehydrogenase. Endocrinology 148: 6100-6106.

33. Kratschmar DV, Calabrese D, Walsh J, Lister A, Birk J, et al. (2012) Suppression of the Nrf2-dependent antioxidant response by glucocorticoids and 11 $\beta$-HSD1mediated glucocorticoid activation in hepatic cells. PLoS One 7: e36774

34. Atanasov AG, Dzyakanchuk AA, Schweizer RA, Nashev LG, Maurer EM, et al. 
Citation: Kratschmar DV, Messner S, Moritz W, Odermatt A (2013) Characterization of a Rat Multi-Cell Type 3D-Liver Microtissue System. J Tissue Sci Eng 4: 130. doi:10.4172/2157-7552.1000130

(2006) Coffee inhibits the reactivation of glucocorticoids by $11 \beta$-hydroxysteroid dehydrogenase type 1: a glucocorticoid connection in the anti-diabetic action of coffee? FEBS Lett 580: 4081-4085.

35. Seglen P O (1976) Preparation of isolated rat liver cells. Methods Cell Biol 13 29-83.

36. Zhong H, Simons J W (1999) Direct comparison of GAPDH, beta-actin, cyclophilin, and $28 \mathrm{~S}$ rRNA as internal standards for quantifying RNA levels under hypoxia. Biochem Biophys Res Commun 259: 523-526.

37. Balázs Z, Nashev LG, Chandsawangbhuwana C, Baker ME, Odermatt A (2009) Hexose-6-phosphate dehydrogenase modulates the effect of inhibitors and alternative substrates of 11 beta-hydroxysteroid dehydrogenase 1 . Mol Cell Endocrinol 301: 117-122.

38. Senesi S, Legeza B, Balazs Z, Csala M, Marcolongo P, et al. (2010) Contribution of Fructose-6-Phosphate to Glucocorticoid Activation in the Endoplasmic Reticulum: Possible Implication in the Metabolic Syndrome. Endocrinology 151: $4830-4839$

39. Nakano S, Inada Y, Masuzaki H, Tanaka T, Yasue S, et al. (2007) Bezafibrate regulates the expression and enzyme activity of 11ß-hydroxysteroid dehydrogenase type 1 in murine adipose tissue and 3T3-L1 adipocytes. Am J Physiol Endocrinol Metab 292: E1213-222.

40. Berger J, Tanen M, Elbrecht A, Hermanowski-Vosatka A, Moller D E, et al. (2001) Peroxisome proliferator-activated receptor-gamma ligands inhibit adipocyte 11beta -hydroxysteroid dehydrogenase type 1 expression and activity. J Biol Chem 276: 12629-12635.

41. Fan Z, Du H, Zhang M, Meng Z, Chen L, et al. (2011) Direct regulation of glucose and not insulin on hepatic hexose-6-phosphate dehydrogenase and 11ß-hydroxysteroid dehydrogenase type 1. Mol Cell Endocrinol 333: 62-69.

42. LeCluyse EL, Witek RP, Andersen ME, Powers MJ (2012) Organotypic liver culture models: meeting current challenges in toxicity testing. Crit Rev Toxicol 42: $501-548$

43. Jigorel E, Le Vee M, Boursier-Neyret C, Bertrand M, Fardel O (2005) Functional expression of sinusoidal drug transporters in primary human and rat hepatocytes. Drug Metab Dispos 33: 1418-1422.

44. Liu X, LeCluyse EL, Brouwer KR, Gan LS, Lemasters JJ, et al. (1999) Biliary excretion in primary rat hepatocytes cultured in a collagen-sandwich configuration. Am J Physiol 277: G12-21.

45. Tong JZ, De Lagausie P, Furlan V, Cresteil T, Bernard O, et al. (1992) Long-term culture of adult rat hepatocyte spheroids. Exp Cell Res 200: 326-332.

46. Prot JM, Briffaut AS, Letourneur F, Chafey P, Merlier F, et al. (2011) Integrated proteomic and transcriptomic investigation of the acetaminophen toxicity in liver microfluidic biochip. PLoS One 6: e21268.

47. Lee WM, Senior JR (2005) Recognizing drug-induced liver injury: current problems, possible solutions. Toxicol Pathol 33: 155-164. 